\title{
Real-Time PCR Assay for Detection of Sphacelotheca reiliana Infection in Maize (Zea mays) Seedlings and Evaluation of Seed Treatment Efficacy
}

\author{
S. J. Anderson, H. E. Simmons, and G. P. Munkvold, Department of Plant Pathology and Microbiology and Seed Science Center, Iowa State
} University, Ames, IA

\begin{abstract}
Anderson, S. J., Simmons, H. E., and Munkvold, G. P. 2015. Real-time PCR assay for detection of Sphacelotheca reiliana infection in maize (Zea mays) seedlings and evaluation of seed treatment efficacy. Plant Dis. 99:1847-1852.

Head smut of maize, caused by the fungus Sphacelotheca reiliana, is an economically important disease in all major maize-producing countries. Although seed treatments are commonly used for management purposes, evaluating these treatments for efficacy is both time consuming and inefficient. Therefore, in order to improve the capacity for evaluating seed treatment fungicides, we developed a real-time PCR-based seedling assay for $S$. reiliana infection. We optimized growth chamber conditions and inoculation methods to achieve infection incidence of 60 to $80 \%$ in inoculated, nontreated controls. The effects of five commercially available fungicidal seed treatment formulations on seedling infection incidence were compared by PCR analysis of root and mesocotyl

tissues. Tebuconazole, fludioxonil, sedaxane, and Maxim Quattro (fludioxonil+mefenoxam+azoxystrobin+thiabendazole) reduced the incidence of infection $(P<0.05)$ compared with the control, but no difference was found between the azoxystrobin treatment and the control. All rates tested for both sedaxane and tebuconazole were equally effective for seeds coated with $10^{6}$ teliospores $\cdot \mathrm{seed}^{-1}$. Sedaxane, at a rate of $0.1 \mathrm{mg} / \mathrm{kernel}$, eliminated seedling infection if seeds were infested with a low inoculum concentration $\left(10^{1}\right.$ teliospores $\left.\cdot \operatorname{see}^{-1}\right)$. The assay developed here is a valuable tool not only for the detection of fungal infection at the seedling stage, but also for testing the relative efficacies of seed treatments for reducing incidence of infection.
\end{abstract}

The phytopathogenic fungus Sphacelotheca reiliana (Kühn) Clint. (syn. Sporisorium reilianum (Kühn) Langdon and Fullerton) is the causal agent of maize head smut. Head smut can lead to sterility in maize as the result of the formation of large masses of black teliospores (i.e., sori) that form in place of tassels and ears, and epidemics can result in up to $80 \%$ yield loss in severely affected fields (Frederiksen 1977). The pathogen has a widespread distribution and is present in Asia, Australia, Europe, North America, and South America. Yield loss occurs when the fungus replaces the ear of a plant with a smut sorus, generally resulting in $100 \%$ yield loss for infected plants. More maize is produced on a yearly basis than any other grain, reflecting its importance in the global market for food and feed production as well as industrial processes, primarily ethanol production for use in biofuels. Given the ability of $S$. reiliana teliospores to remain infectious both in soil and on seed (Pataky 1999), the need to effectively control this pathogen has become increasingly important in both commercial grain production as well as maize seed production.

In maize, the black echinulate teliospores of $S$. reiliana are dispersed during harvest and are subsequently spread by wind or by adhering to the seed coat (Pataky 1999). When conducive soil conditions are present, teliospores germinate to form a basidium (or promycelium) containing four cells. This structure produces yeast-like haploid basidiospores that reproduce via budding (Martinez et al. 2002). When two compatible strains (differing at mating loci a and b) meet, conjugation tubes are formed and hyphae fuse to form a diploid infection hypha (Schirawski et al. 2005). The infection hypha are able to penetrate the root tissue of maize seedlings up to 6 weeks after seed germination and the fungus then grows along with the meristematic tissue, effecting minimal or no change in plant cells and generally causing no symptoms during the vegetative stages of maize growth (Matyac and Kommedahl 1985). After the transition of the plant from vegetative growth stages to the reproductive growth

Corresponding author: G. P. Munkvold, E-mail: munkvold@iastate.edu

Accepted for publication 24 November 2014.

http://dx.doi.org/10.1094/PDIS-07-14-0776-RE

(C) 2015 The American Phytopathological Society stages, fungal hyphae invade cells of the host reproductive structures and can destroy them leading to sporogenesis. Cells that would have given rise to the tassel and ear are replaced with sporogenous $S$. reiliana cells, usually resulting in sterility of these maize tissues. In place of ears or tassels, a mass of black spores (a sorus, pl. sori) is formed, enveloped by a thin membrane called the peridium (Martinez et al. 2002; Schirawski et al. 2005).

During harvest, the sori of infected plants are ruptured and the teliospores are released and disseminated. The teliospores are released into the soil and serve as a source of inoculum, remaining viable for at least 3 years and under seed storage conditions, teliospores adhering to seed surfaces may remain viable for much longer periods of time (Allan and Duran 1979). These contaminated seeds can aid in the dissemination of the fungus, transporting it to new areas where it can be seed transmitted, causing seedling infection, or it can contaminate soils, causing disease in a later crop (Pataky 1999). Prevention of seedborne disease spread is an important goal for the maize seed industry and a concern for phytosanitary regulatory agencies.

Current management strategies include the use of host resistance and seed- or soil-applied chemical treatment. As most commercially available hybrids lack a high level of resistance to this pathogen, chemical control is a common strategy in high-risk areas. Because initial infection occurs during the seedling stage, this disease can be managed effectively with seed treatment fungicides; however, available data on the efficacy of specific active ingredients are limited. Currently used products such as tebuconazole are often applied at high rates, which can be phytotoxic to maize plants (Stienstra et al. 1985; Wright et al. 2006; Yang et al. 2014; Zeng et al. 2010). Therefore, there is a pressing need to evaluate new active ingredients that will effectively reduce $S$. reiliana infection without producing deleterious side effects on the crop.

Testing the efficacy of seed treatments typically depends on field trials and observations of disease symptoms. However, not only are field trials costly and time-consuming, but they usually rely on natural soil infestation, which can lead to highly variable results. Variations in weather can also contribute to variable trial results, particularly if infection is reduced under conditions of extremely wet soils or extreme temperatures (Martinez et al. 2003). Disease assessments are very laborious and can lead to further dissemination of the disease via teliospore contamination of clothing. Thus, an alternative assay, using an assessment 
of seedling infection, could greatly facilitate seed treatment testing by providing more rapid and consistent results without the risk of unintentional pathogen spread. To this end, we developed and validated an assay that allows for (1) consistent $S$. reiliana infection of maize seedlings through a natural infection process, (2) sensitive molecular detection of this infection, and (3) a procedure to screen seed treatment active ingredients for their ability to reduce seedling infection. In addition, we used the assay to characterize the effect of one seed treatment on seedling infection over a range of inoculum levels.

\section{Materials and Methods}

Seed coating. Teliospores of $S$. reiliana were collected from naturally infected plants in Sacramento Co., CA, where high disease incidence facilitates collection of large numbers of teliospores. Smut galls were broken up and sieved to remove plant material and other debris. Teliospores were then air-dried in paper sacks, stored in glass vials, and shipped to Iowa under the conditions of APHIS-PPQ permit P526P-11-02346. Teliospores were stored at $4{ }^{\circ} \mathrm{C}$ until use. All tools and materials that contacted teliospores were either bleached or autoclaved according to APHIS permit conditions. Teliospores were surface disinfested with bleach to reduce the presence of other pathogens according to the protocol adapted from Bruckart and Eskandari (2002), and viability was assessed by spreading a spore suspension on antibiotic-amended dextrose agar and incubating at $27^{\circ} \mathrm{C}$ (Osorio and Frederiksen 1998). Germination was visually determined using a compound microscope and teliospores were counted as germinated if the promycelium or basidium was present. Teliospores consistently germinated at a rate of approximately $60 \%$ after 3 days at $27^{\circ} \mathrm{C}$. In preliminary experiments, several inoculation methods were compared, including soil infestation procedures, direct application of spore suspensions to the germinated seedling, and coating of the seeds with teliospores (data not shown). We attained the most consistent results with the seed coating method, and therefore used this inoculation.

Preliminary trials were conducted to optimize the concentration of inoculum for seed coating. Three concentrations of inoculum were tested: $10^{5}, 10^{6}$, and $10^{7}$ teliospores seed $^{-1}$. A concentration of $10^{6}$ teliospores seed $^{-1}$ was chosen for subsequent experiments to represent the maximum inoculum load as this concentration achieved the highest infection incidence without deterring seedling emergence. In order to target $10^{6}$ teliospores $\cdot$ seed $^{-1}$, teliospores $(0.25 \mathrm{~g})$ were suspended in $10 \mathrm{ml}$ of a DAT (3\% dextrose w/v, 0.1\% agar w/v, 3 drops tween 20 per $100 \mathrm{ml}$ total volume) solution. One hundred grams of maize seed of hybrid TA-685-02 (TA Seeds, Jersey Shore, PA) were placed in a Ziploc bag, $10 \mathrm{ml}$ of spore suspension was added, and the bag was lightly kneaded to ensure even seed coating. Under a sterile biosafety hood, the bag was opened to allow the spore suspension to dry and adhere to the seeds. To confirm the inoculum level per seed, 10 dried seeds were arbitrarily chosen from the bag and suspended in $10 \mathrm{ml}$ of water in a 50-ml centrifuge tube with one drop of tween. The tube was agitated to dislodge the teliospores from the seed coat and samples of the suspension were taken for spore counts on a hemocytometer. Further experiments were conducted with lower inoculum levels, ranging from $10^{6}$ to $10^{1}$ teliospores seed $^{-1}$. These inoculum concentrations were achieved by 10 -fold serial dilutions of the original suspension.

After the seeds were coated with teliospores and allowed to dry, fungicidal seed treatments were applied.
Seed treatment experiments. Three types of experiments were conducted using similar methods but different treatments. In experiment 1 , several fungicidal seed treatments were compared using seed coated with $10^{6}$ teliospores'seed ${ }^{-1}$. In experiment 2 , sedaxane was tested at three different rates using seed coated with $10^{6}$ teliospores seed $^{-1}$. In experiment 3 , the efficacy of sedaxane was tested over a range of inoculum loads on the seed.

There were seven treatments in experiment 1 (rates shown in Table 1): (1) nontreated control, (2) fludioxonil, (3) Maxim Quattro, (4) azoxystrobin, (5) tebuconazole $\left(0.019 \mathrm{mg} \cdot \mathrm{seed}^{-1}\right),(6)$ tebuconazole $\left(0.028 \mathrm{mg} \cdot \mathrm{seed}^{-1}\right)$, and $(7)$ tebuconazole $\left(0.038 \mathrm{mg} \cdot \mathrm{seed}^{-1}\right)$. There were four treatments in experiment 2: (1) nontreated control, (2) sedaxane $\left(0.05 \mathrm{mg} \cdot \mathrm{seed}^{-1}\right),(3)$ sedaxane $\left(0.075 \mathrm{mg} \cdot \mathrm{seed}^{-1}\right)$, and (4) sedaxane $\left(0.1 \mathrm{mg} \cdot \mathrm{seed}^{-1}\right)$. Experiment 3 was a $2 \times 6$ factorial, with two levels of seed treatment (nontreated and sedaxane at $0.1 \mathrm{mg} \cdot \mathrm{seed}^{-1}$ ) and six levels of inoculum concentration $\left(10^{6}, 10^{5}, 10^{4}, 10^{3}, 10^{2}\right.$, and $10^{1}$ teliospores'seed ${ }^{-1}$ ). For all experiments, hybrid TA-685-02 was used and seed treatment was performed using a small bowl seed treater (Hege 11) and five commercial seed treatments were used: fludioxonil (Maxim 4FS, Syngenta); fludioxonil + mefenoxam + azoxystrobin + thiabendazole (Maxim Quattro, Syngenta); azoxystrobin (Dynasty, Syngenta); sedaxane (Vibrance, Syngenta); tebuconazole (Raxil 2.6F, Bayer Crop Science) (specific treatments and rates are listed in Table 1).

In each experiment, 15 replicate seeds per treatment were sown in a completely randomized design in the growth chamber, and each experiment was conducted three times. Spore-coated and fungicidetreated seeds as well as nontreated control seeds (spore-coated and mock-treated with colorant and polymer) were planted at a depth of $4 \mathrm{~cm}$ in autoclaved field soil in $150 \mathrm{~cm}^{3}$ cone-tainers (Cone-tainer Nursery, Canby, OR) and placed in a growth chamber at Iowa State University. The conditions inside the growth chamber were as follows: day temperature $27^{\circ} \mathrm{C}$; night temperature $24^{\circ} \mathrm{C}$; day length $15 \mathrm{~h}$; and relative humidity $70 \%$. Plants were given approximately $10 \mathrm{ml}$ of water daily and were grown for approximately 4 weeks (growth stage V3), at which point whole plants were collected and processed.

Seedlings were cleaned of visible soil by rinsing under running tap water and then surface disinfected by submersion in $10 \% \mathrm{NaOCl}$ solution with agitation for $2 \mathrm{~min}$. Plants were rinsed twice in sterile water for $30 \mathrm{~s}$ each time. Under a sterile biosafety hood, tissue samples were excised from the crown, mesocotyl, seminal root, and nodal root tissues. Crown tissue was sampled by removing a cross section approximately $0.5 \mathrm{~cm}$ in length just above the protrusion of the nodal roots. Mesocotyl samples were taken by removing a $0.5 \mathrm{~cm}$ cross section halfway between the seed and the nodal root protrusion. Both the seminal and nodal root tissues were sampled by twisting all the roots of one type together and then removing a $0.5 \mathrm{~cm}$ cross section near the root base.

Tissue samples were placed in individual 1.2-ml wells in a 96-well grinding plate (Fisher Scientific) and lyophilized at $-56^{\circ} \mathrm{C}$ and 0.002 $\mathrm{mBar}$ for 1 to 2 days. A metal bead $(4.5 \mathrm{~mm})$ was then placed in each well and the plate was placed in a tissue grinder (Genogrinder), and ground at $1,000 \mathrm{rpm}$ for $1 \mathrm{~min}$.

DNA extraction and qPCR. Genomic DNA was extracted using protocol adapted from Rogers and Bendich (1985). Six hundred microliters of CTAB (cetyltrimethylammoniumbromide) extraction buffer $(0.1 \mathrm{M}$ Tris-HCl, $\mathrm{pH} 7.5,0.7 \mathrm{M} \mathrm{NaCl}, 10 \mathrm{mM}$ EDTA, $1 \%$ $\mathrm{CTAB})+2 \% 2$-mercaptoethanol was added to each well and the

Table 1. Fungicide active ingredients, trade names, and application rates for products tested in growth chamber experiments for control of seedling infection by Sphacelotheca reiliana ${ }^{\mathrm{a}}$

\begin{tabular}{lll}
\hline Fungicide active ingredient & Trade name & \multicolumn{1}{c}{ Treatment rate(s) (mg/kernel) } \\
\hline Fludioxonil & Maxim 4FS & 0.012 \\
Fludioxonil (Flu) + Azoxystrobin (Azo) + & Maxim Quattro & $0.0064(\mathrm{Flu})+0.0025(\mathrm{Azo})+0.05(\mathrm{Thi})+0.005(\mathrm{Mef})$ \\
$\quad$ Thiabendazole (Thi) + Mefenoxam (Mef) & Dynasty & 0.0025 \\
Azoxystrobin & Raxil & $0.019,0.028,0.038$ \\
Tebuconazole & Vibrance & $0.05,0.075,0.1$ \\
Sedaxane & P &
\end{tabular}

${ }^{a}$ Raxil provided by Bayer Crop Science (Monheim, Germany) all other fungicides provided by Syngenta Crop Protection (Basel, Switzerland). 
tubes were incubated at $65^{\circ} \mathrm{C}$ for $1 \mathrm{~h}$ and inverted every $10 \mathrm{~min}$. The liquid from each sample was drawn off and transferred to a sterile 1.5$\mathrm{ml}$ microfuge tube. Six hundred microliters of 24:1 chloroformisoamyl alcohol was added to each of these tubes and each tube was inverted several times. Each tube was centrifuged for $10 \mathrm{~min}$ at $13.2 \times 10^{3} \mathrm{rpm}$ and the upper layer of liquid was drawn off and transferred to a sterile 1.5-ml microfuge tube. Six hundred microliters of cold isopropanol was added to each of the tubes, which were then centrifuged for $10 \mathrm{~min}$ at $13.2 \times 10^{3} \mathrm{rpm}$. From each tube, the supernatant was poured off and the DNA pellet retained in the tube. The pellet was then washed with $70 \%$ ethanol and dried. The pellet was eluted in $200 \mu \mathrm{l}$ of ultrapure water.

In preliminary experiments, we ascertained that the previously published primers for conventional PCR (Xu et al. 1999) were not sufficiently sensitive to detect low levels of $S$. reiliana DNA in plant tissue. Therefore, we designed primers for real-time PCR using Primer Express 3 (Applied Biosystems Int.) and sequences published on GenBank that would amplify a 74-bp amplicon that is located in the 18s ribosomal ITS region (GenBank Accession No. KF706438.1). The forward primer sequence is $5^{\prime}$-GCTCGCCTTTCGCTCTCTCT- 3 ', and the reverse primer sequence is $5^{\prime}$-GCCTCCGAAGCCCTGA TAGT-3'. Specificity of the primers was confirmed via a NCBI standard nucleotide BLAST search that showed the primers had low homology $(\leq 55 \%)$ with other fungal species found on maize including the common smut pathogen Ustilago maydis, although we did not test the primers against other fungi.

DNA was extracted directly from teliospores, from axenically grown maize tissue, and from maize tissue known to be infected with $S$. reiliana; these samples were used for validation of the primers. Each type of DNA was standardized to a concentration of $10 \mathrm{ng} / \mu \mathrm{l}$ for evaluation of the primers. DNA from teliospores, axenic maize, and infected maize as well as a mixture of teliospore DNA with axenic maize DNA were tested in triplicate. Negative controls (in which water replaced the template DNA) were used to ensure the absence of primer dimers and contamination. Gradient PCR and varying primer concentrations were used to determine optimal PCR conditions (data not shown).

All PCR reactions were performed using an Applied Biosystems StepOne Plus real time PCR system and Applied Biosystems 96-well 0.2-ml plates. Final PCR conditions were as follows: $20 \mu \mathrm{l}$ total reaction volume was used per sample well; $2 \mu \mathrm{l}$ of sample DNA extract, $10 \mu \mathrm{l}$ Applied Biosystems SYBR Green PCR Master Mix, $0.07 \mu \mathrm{l}$ forward primer, $0.07 \mu \mathrm{l}$ reverse primer, and $7.86 \mu$ l ultrapure water. The final PCR parameters were as follows: precycle stage, 5 min at $95^{\circ} \mathrm{C} ; 40$ cycles of denaturing, $1 \mathrm{~min}$ at $95^{\circ} \mathrm{C}$; and 40 cycles of annealing and extension, $30 \mathrm{~s}$ at $60^{\circ} \mathrm{C}$. A standard curve was developed from a 10-fold serial dilution of DNA from direct teliospore extraction with a starting concentration of $10 \mathrm{ng} / \mu \mathrm{l}$ down to $1 \mathrm{pg} / \mu \mathrm{l}$ (Fig. 1); the accompanying amplification curve is shown in Figure 2.

Plant tissue samples (seminal root, nodal root, mesocotyl, and crown) from each experiment were analyzed separately by realtime PCR. Individual plants were considered infected if threshold amplification occurred for any one or more of the four types of excised plant tissue. ANOVA was performed on infection incidence data using the SAS software package (Cary, NC) by generalized linear model with Bonferroni corrections to detect differences between treatments. The data from the three repetitions of each experiment were combined for analysis.

\section{Results}

S. reiliana DNA was detected from all sample types except for the negative controls: axenic maize tissue and the no-template control wells. Melt curve analysis showed a single peak corresponding to the primer amplicon (data not shown). This real-time PCR assay reliably detected $S$. reiliana DNA at concentrations ranging from $120 \mathrm{ng} / \mu \mathrm{l}$ down to as low as $1 \mathrm{pg} / \mu \mathrm{l}$.

In experiment 1 , incidence of infection in the nontreated controls ranged from 65 to $80 \%$. Tebuconazole, fludioxonil, and Maxim Quattro (fludioxonil + azoxystrobin + thiabendazole + mefenoxam) reduced $S$. reiliana infection (by approximately 70,50 , and $60 \%$,

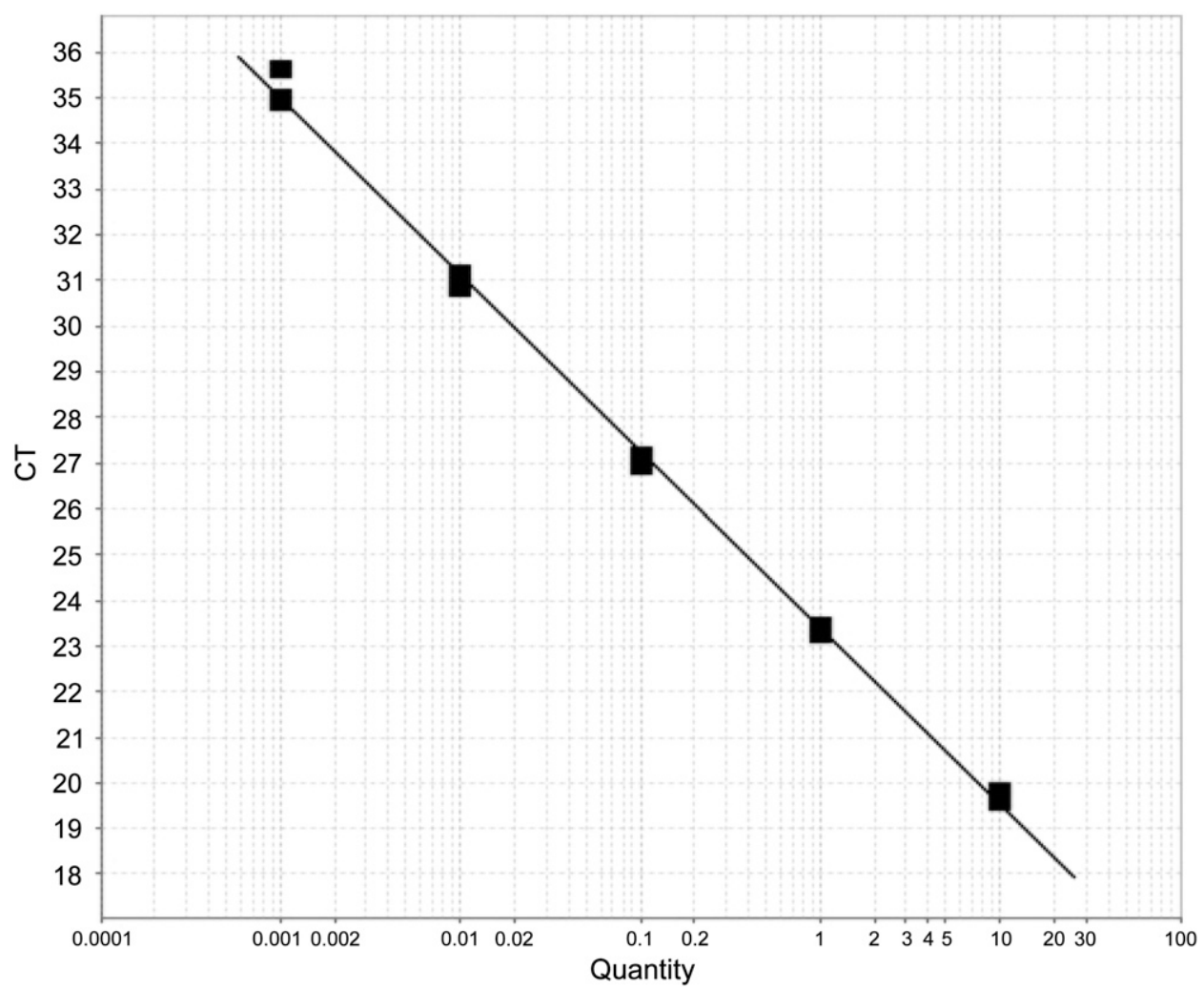

Fig. 1. Standard curve obtained from 10-fold serial dilution of DNA extracted from teliospores of Sphacelotheca reiliana. Each concentration was evaluated in triplicate and each point represents one sample. $R^{2}=99.8 \%$. Efficiency $=100.1 \%$. 
respectively) compared with the control $(P<0.01)$, whereas azoxystrobin (standard error among repeat trials was 9\%) alone did not reduce infection. There were no differences in incidence of infection among the three rates of tebuconazole (standard error among repeat trials for low, medium, and high rates was 6,3 , and $6 \%$, respectively) tested $(P<0.01)$, and also no differences among the tebuconazole, fludioxonil (standard error among repeat trials was 6\%), and combination (Maxim Quattro) treatments (standard error among repeat trials was $10 \%$ ) (Fig. 3).

In experiment 2, the application of sedaxane at all three treatment rates (standard error among the repeat for low, medium, and high rates was 8,6 , and $7 \%$, respectively) reduced infection compared with the control $(P<0.01)$. Incidence did not differ significantly among the rates. Results were similar to experiment 1, with $68 \%$

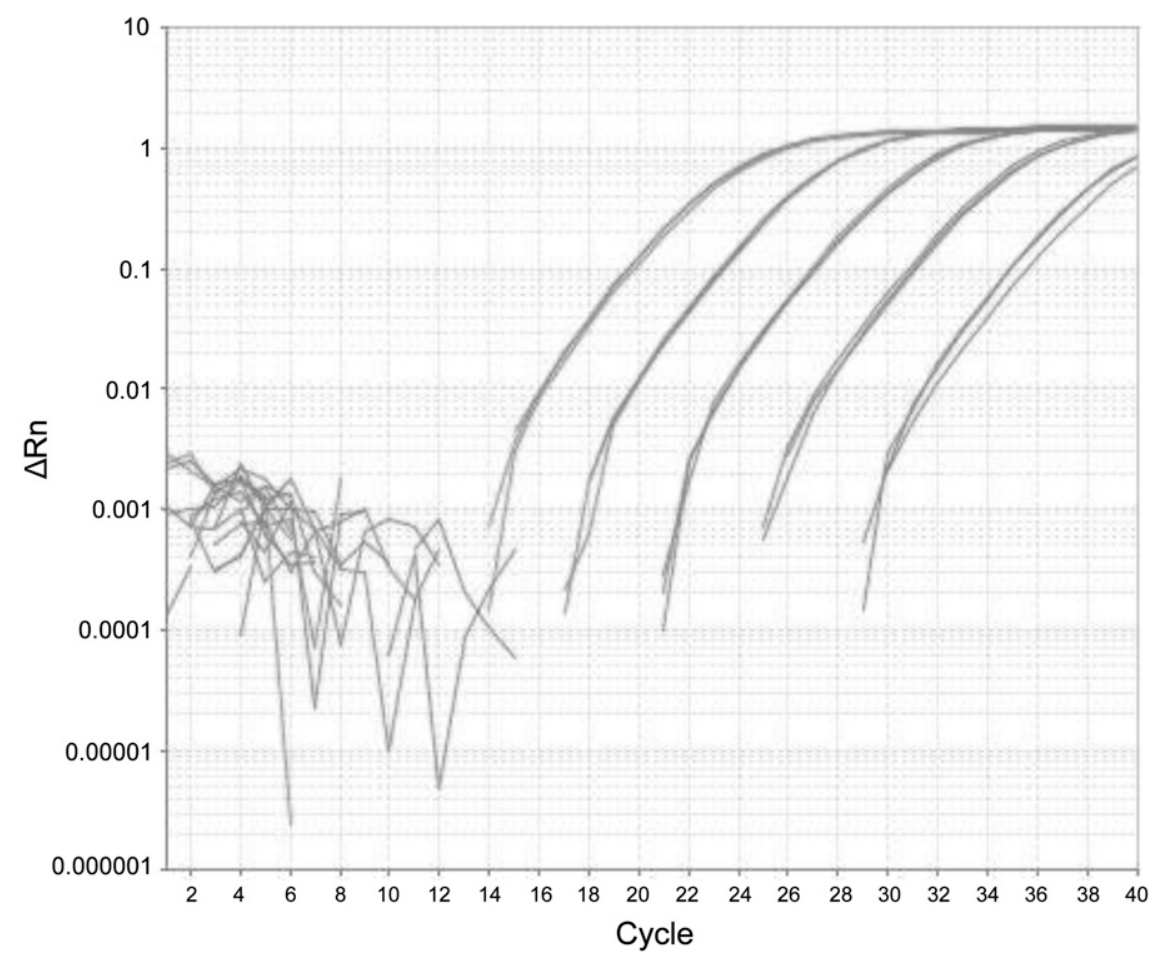

Fig. 2. Amplification plot obtained by 10 -fold serial dilution of DNA extracted for spore tissue. Each dilution was tested in triplicate. Leftmost curve represents a starting concentration of $10 \mathrm{ng} / \mu \mathrm{l}$.

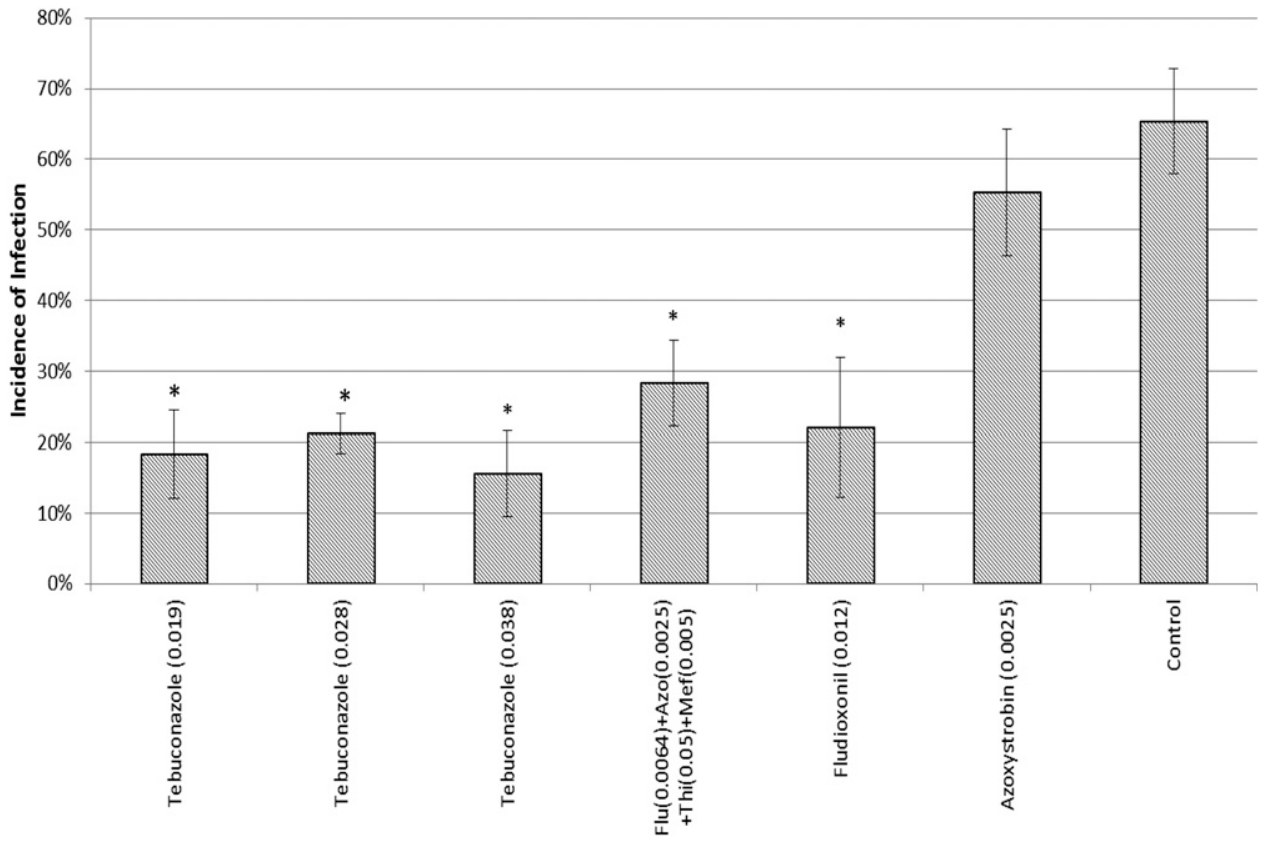

Fig. 3. Incidence of infection detected via RT-PCR in seedlings of maize hybrid TA-685-02 treated with fungicidal seed treatments. Treatment names are described in Table 1 and were compared to a control that was inoculated and mock treated with colorant and polymer only. Numbers in parenthesis represent active ingredient rate in mg.seed ${ }^{-1}$. Each bar represents the average of three trials. Error bars represent standard error. Flu $=$ Fludioxonil, Azo $=$ Azoxystrobin, Thi $=$ Thiabendazole, Mef $=$ Mefenoxam. Bars marked with an asterisk $\left(^{*}\right)$ differed significantly from the control at the $P=0.01$ level. 
infection incidence in the control, reduced by approximately two thirds in the sedaxane treatments (Fig. 4).

In experiment 3 , sedaxane $\left(0.1 \mathrm{mg} \cdot \mathrm{seed}^{-1}\right)$ was applied to seeds coated with six different inoculum rates $\left(10^{6}, 10^{5}, 10^{4}, 10^{3}, 10^{2}\right.$, and $10^{1}$ teliospores $\cdot$ seed $^{-1}$ and standard error among repeat trials of each rate was $5,4,4,2,1$, and $0 \%$, respectively). When compared with a nontreated control (same inoculum rates with no sedaxane), a 15 to $25 \%$ decrease of infection incidence was observed in all the inoculum rates. Sedaxane was found to eliminate infection when seeds were coated at a rate of 10 teliospores $\cdot \operatorname{seed}^{-1}$ (Fig. 5).

\section{Discussion}

Our results indicate that tebuconazole, fludioxonil, and sedaxane are equally effective at reducing $S$. reiliana infection. That the three rates of tebuconazole tested showed no statistical differences suggests that the lower range of recommended rates is adequate even with high levels of inoculum. This has positive implications for disease management both in terms of cost efficiency and avoidance of potential phytotoxic effects. Yang et al. (2014) found that $0.015 \mathrm{mg} / \mathrm{seed}$ tebuconazole sufficiently reduced head smut incidence compared with their control (reductions in disease varied from approximately 57 to $91 \%$ ) and this rate is similar to our lowest rate $(0.019 \mathrm{mg} / \mathrm{seed})$ with which we recorded reductions in infection incidence of approximately 50\% compared with our control.

The comparison among fludioxonil, azoxystrobin, and Maxim Quattro (fludioxonil + azoxystrobin + thiabendazole + mefenoxam) indicated that fludioxonil is likely the active ingredient in Maxim Quattro that is effective against head smut infection. Mefenoxam and thiabendazole have not been shown to be effective against S. reiliana; fludioxonil alone reduced infection as effectively as the combination of fludioxonil with other active ingredients (Maxim Quattro) and azoxystrobin alone was not effective. Although the fludioxonil rate in the combination treatment was half that of the fludioxonil alone, the failure of azoxystrobin to significantly reduce infection compared with the control, indicates that fludioxonil was the effective ingredient in the Maxim Quattro combination. In

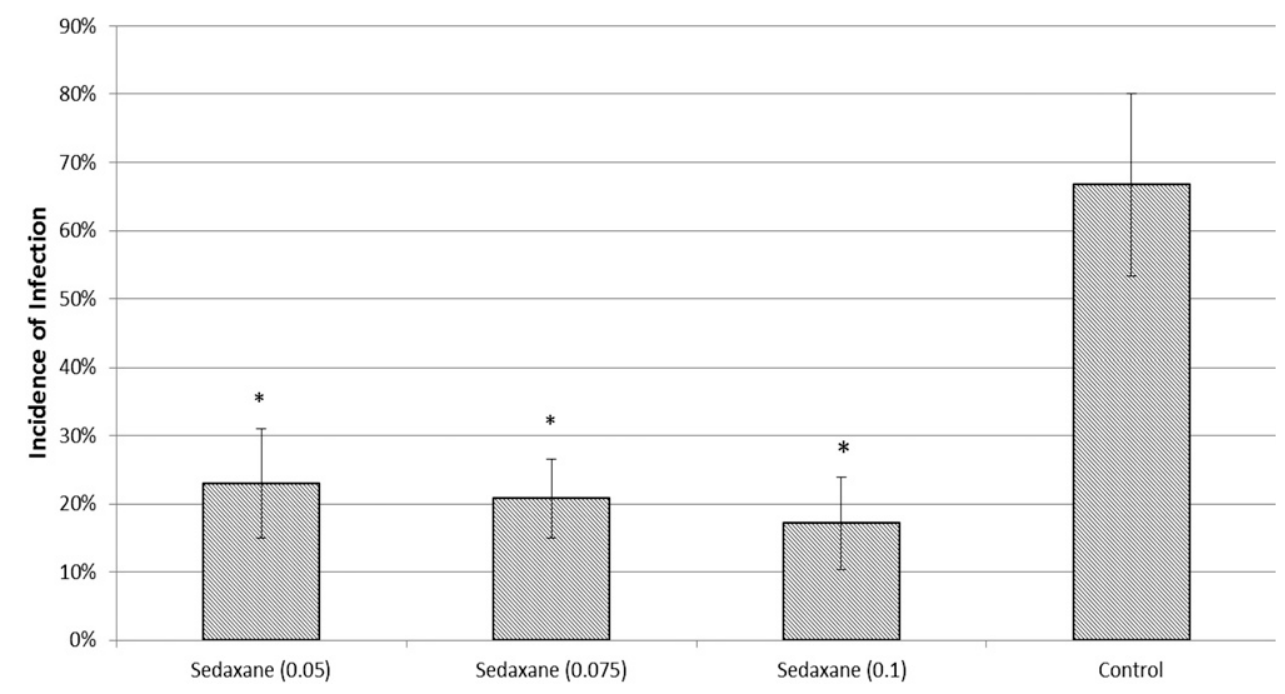

Fig. 4. Incidence of pathogen infection detected via RT-PCR in seedlings maize hybrid TA-685-02 treated with three rates of sedaxane. Treatments were compared to a control that was inoculated and mock treated with a colorant and polymer only. Numbers in parenthesis represent active ingredient rate in mg.seed ${ }^{-1}$. Each bar represents the average of three trials. Error bars represent standard error. Bars marked with an asterisk ( $\left.{ }^{*}\right)$ differed significantly for from the control at the $P=0.01$ level.

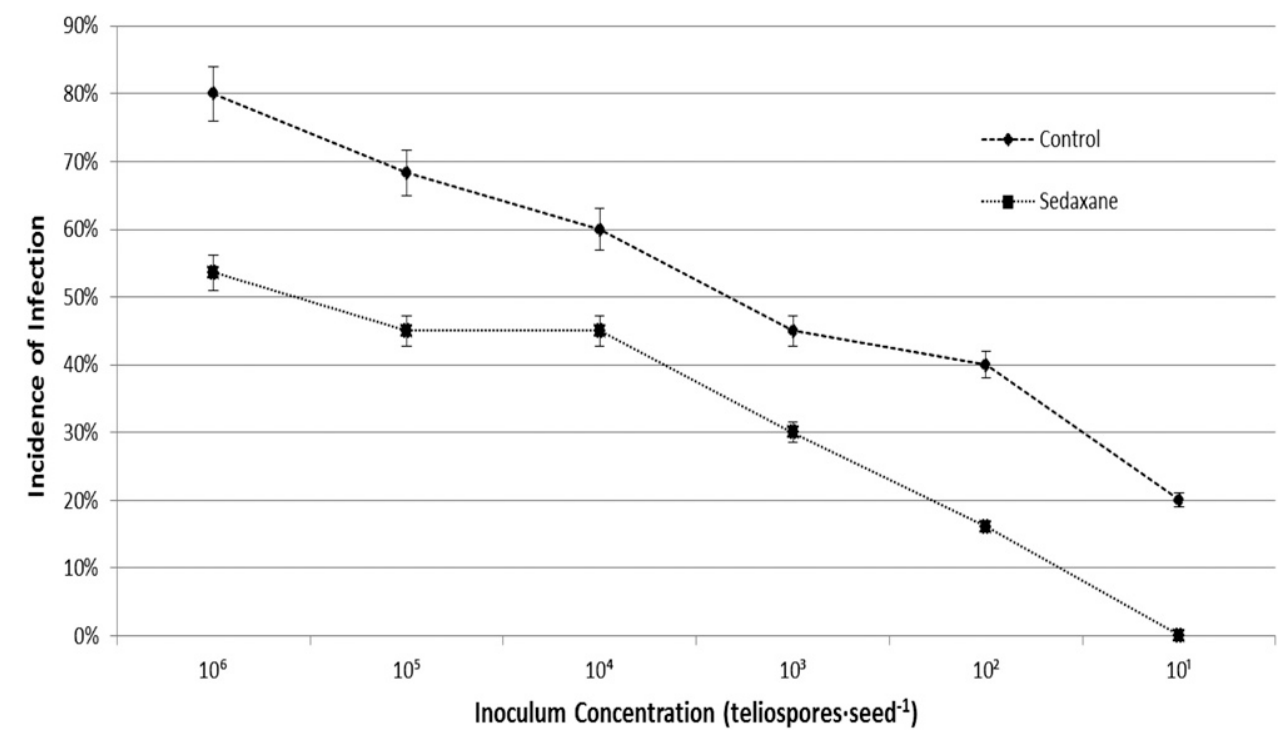

Fig. 5. Incidence of infection detected via RT-PCR in seedlings of maize hybrid TA-685-02. Horizontal axis represents inoculum load in spores·seed ${ }^{-1}$. Sedaxane $\left(0.1 \mathrm{mg}^{-5} \cdot \mathrm{seed}^{-1}\right)$ was used to treat inoculated seed and was compared to an inoculated control that was mock treated with colorant and polymer. Each data point represents the average of two trials. Error bars represent standard error. 
contrast, Wright et al. (2006) found that azoxystrobin significantly reduced the percentage of symptomatic plants. We found that sedaxane was effective in reducing infection incidence and although decreased infection was observed with increased application rates, there was no significant rate effect. Thus, the lower range of recommended rates for sedaxane appears to be adequate for protection from $S$. reiliana infection. Other studies (Stienstra et al. 1985; Wright et al. 2006) reported that propiconazole and carboxin were also effective for reducing smut incidence, but those ingredients were not tested by our assay.

Sedaxane eliminated infection from seedborne inoculum, when inoculum was applied at a rate of $10^{1}$ teliospores seed $^{-1}$. In order to ensure the safety of seed originating from areas in which head smut is known to occur, it is desirable to demonstrate that seed treatment can eliminate or nearly eliminate the risk of seed transmission. Our data indicate that this is feasible, if inoculum levels are $10^{1}$ teliospores $^{\prime}$ seed $^{-1}$ or less. Although the range of inoculum levels per seed under natural conditions is unknown, it is unlikely to be as high as $10^{6}$ teliospores $\cdot$ seed $^{-1}$ but may be higher than $10^{1}$ teliospores $\cdot$ seed $^{-1}$. Additional data are needed on naturally occurring inoculum levels in order to assess whether current seed treatment practices are adequate to eliminate the risk associated with seedborne inoculum.

In this study, S. reiliana inoculum was applied to seed in order to mimic infection from naturally seedborne inoculum and to maximize consistency of infection in the assay. Applying teliospores to seed ensured the presence of high levels of inoculum in the seedling infection count and provided an accurate basis for comparisons among seed treatments. Absolute levels of infection may differ when the primary source of inoculum is soilborne. However, results of the assay developed in this study provide a basis for determining the relative performance among seed treatment active ingredients. Osorio and Frederiksen (1998) and Thakur et al. (2007) explored inoculation techniques that utilized sporidial preparations of $S$. reiliana and either the injection of the suspensions into plant tissues or the placement of these suspensions onto the germinated seed. Injection into plant tissues generally results in higher infection rates but this inoculation procedure bypasses one of the most important resistance mechanisms, viz. initial penetration of root tissues by the pathogen, and would not be appropriate for seed treatment evaluation. Osorio and Frederiksen (1998) found that $14.5 \%$ of maize seedlings inoculated by application of the sporidial suspension to germinated seed showed head smut symptoms while another $68 \%$ percent were observed to be sterile. The authors speculated that these plants may be infected, thus the sterility, but lacked other disease symptoms.

Although it is possible to quantify pathogen DNA using the realtime PCR assay developed in this study, the relationship between DNA quantity and symptom development is unknown, and we limited our interpretation of the PCR results to infection incidence in seedlings and the reduction of this infection incidence with fungicide seed treatments. Some infected seedlings do not become symptomatic plants (Anderson et al. 2013), and the relationship between seedling infection incidence and incidence of smutted ears has not been established. However, plants are known to be susceptible only for a short period during the seedling stage (Matyac and Kommedahl 1985); therefore, prevention of seedling infection can be assumed to be an effective disease management tactic. Presumably, the absence of seedling infection corresponds to reduced risk of disease, and is an appropriate measure of seed treatment efficacy. The assay developed here can be used to perform DNA quantification and future work needs to establish the relationship between the observed levels of pathogen DNA in different plant tissues and plant developmental stages to ultimate disease incidence. These results could be used to elucidate disease development and host resistance mechanisms. The results presented here demonstrate that seed treatment efficacy can be assessed efficiently and accurately under growth chamber conditions using the real-time PCR-based seedling assay. The real-time primers presented here should be further validated for specificity to $S$. reiliana by examining possible cross-reaction with other closely related species. With the growth chamber assay, environmental conditions can be controlled to simulate conditions that result in high infection incidence of S. reiliana. It is under these conditions that the true potential of a seed treatment to combat head smut is realized. Furthermore, these results indicate that currently available seed treatments provide significant reductions in S. reiliana infection. Sedaxane, tebuconazole, and fludioxonil were effective alone or in combination with other active ingredients. Although we did not test the combination of sedaxane and Maxim Quattro, this is also a commercially available combination and our results suggest that it should provide effective protection against head smut. The assay developed here can be a useful tool for further evaluation of new active ingredients and combinations, reducing time expenditure and cost and allowing new active ingredients to enter the market faster.

\section{Acknowledgments}

This work was supported by funds from Bayer Crop Science, Syngenta Crop Protection, and Valent Biosciences. We are grateful for the preliminary work on this project conducted by Michele Beattie and Dr. Anania Fessehaie. Dr. Ron French (Texas A\&M University) contributed ideas to this work and provided infected material for development and validation of the PCR assay. Teliospores were kindly collected and provided to us by Mark Mancl (DuPont Pioneer, Inc.). Dr. Gilberto Olaya (Syngenta Crop Protection) assisted with procedures for $S$. reiliana teliospore germination.

\section{Literature Cited}

Allan, R. F., and Duran, R. 1979. The influence of aging on teliospore germination. Plant Dis. Rep. 63:841-842.

Anderson, S., Beattie, M., Lübbersted, T., Munkvold, G. 2013. Real-time PCR assay for assessing the interaction of Sphacelotheca reiliana with maize seedlings. Phytopathology 103(Suppl.):S2.7.

Bruckart, W., and Eskandari, F. 2002. Factors affecting germination of Puccinia jaceae var. solstitialis teliospores from yellow starthistle. Phytopathology 92: 355-360.

Frederiksen, R. A. 1977. Head smuts of corn and sorghum. Pages 89-105 in: Proceedings of the 32nd Annual Corn Sorghum Research Conference. American Seed Trade Association, Washington DC.

Martinez, C., Roux, C., Jauneau, A., Becard, G., and Dargent, R. 2003. Effect of water potential on a haploid strain of Sporisorium reilianum $\mathrm{f}$. sp. zea. Plant Soil 251:65-71

Martinez, C., Roux, C., Jauneau, A., and Dargent, R. 2002. The biological cycle of Sporisorium reilianum f.sp. zeae: an overview using microscopy. Mycologia 94:505-514.

Matyac, C., and Kommedahl, T. 1985. Occurrence of chlorotic spots on corn seedlings infected with Sphacelotheca reiliana and their use in evaluation of head smut resistance. Plant Dis. 69:251-254.

Osorio, J., and Frederiksen, R. 1998. Development of an infection assay for Sporisorium reilianum, the head smut pathogen on sorghum. Plant Dis. 82: 1232-1236.

Pataky, J. K. 1999. Smuts. Pages 33-35 in: Compendium of Corn Diseases, 3rd Ed., D. G. White, ed. APS Press, St. Paul, MN.

Rogers, S., and Bendich, A. 1985. Extraction of DNA from milligram amounts of fresh, herbarium and mummified plant tissues. Plant Mol. Biol. 5:69-76.

Schirawski, J., Heinze, B., Wagenknecht, M., and Kahmann, R. 2005. Mating type loci of Sporisorium reilianum: novel pattern with three a and multiple B specificities. Eukaryot. Cell 4:1317-1327.

Stienstra, W. C., Kommedahl, T., Stromberg, E. L., Matyac, C. A., Windels, C. E. and Morgan, F. 1985. Suppression of corn head smut with seed and soil treatments. Plant Dis. 69:301-302.

R. P. Thakur, B. V. S. Reddy, and K. Mathur, eds. 2007. Screening Techniques for Sorghum Diseases. Information Bulletin No. 76. International Crops Research Institute for the Semi-Arid Tropics, Patancheru, Andhra Pradesh, India.

Wright, P. J., Fullerton, R. A., and Koolaard, J. P. 2006. Fungicide control of head smut (Sporisorium reilianum) of sweetcorn (Zea mays). New Zealand J. of Crop Hort. Sci. 34:23-26.

Xu, M. L., Melchinger, A. E., and Lübberstedt, T. 1999. Species-specific detection of the maize pathogens Sporisorium reiliana and Ustilago maydis by dot blot hybridization and PCR-based assays. Plant Dis. 83:390-395.

Yang, D., Wang, N., Yan, X., Shi, J., Zhang, M., Wang, Z., and Yuan, H. 2014. Microencapsulation of seed-coating tebuconazole and its effects on physiology and biochemistry of maize seedlings. Colloids Surf. B Biointerfaces 114:241-246.

Zeng, D., Mei, X., and Wu, J. 2010. Effects of an environmentally friendly seed coating agent on combating head smut of corn caused by Sphacelotheca reiliana and corn growth. J. Ag. Biotechnol. Sustain. Dev. 2:108-112. 